ఠ

\title{
Relapsed Hodgkin lymphoma in adolescents: focus on current high-dose chemotherapy and autologous stem cell transplant
}

REVIEW

This article was published in the following Dove Press journal:

Clinical Oncology in Adolescents and Young Adults

8 May 2014

Number of times this article has been viewed

Gregory MT Guilcher'

Douglas A Stewart ${ }^{2}$

'University of Calgary, Section of Hematology/Oncology/Transplant, Alberta Children's Hospital, Calgary, Canada; ${ }^{2}$ University of Calgary,

Division of Medical Oncology, Tom

Baker Cancer Centre, Calgary, Canada

Correspondence: Gregory MT Guilcher Section of Pediatric Hematology/ Oncology/Transplant, Alberta Children's Hospital, 2888 Shaganappi Trail NW,

Calgary, Alberta, Canada

Tel +l 4039557272

Fax +l 4039552645

Email greg.guilcher@

albertahealthservices.ca
Abstract: Hodgkin lymphoma is one of the most common cancers of adolescence and young adulthood. Most patients are cured of their disease, with very high cure rates in early stage disease and improving rates of cure even in those who present with advanced stage disease. Upfront therapy often involves chemotherapy and radiation therapy; with improving cure rates, acute and late effects of therapy are informing newer treatment protocols to avoid toxicities. Those children and adolescents with refractory or relapsed disease have lower rates of cure and generally warrant more intensive therapy. High-dose chemotherapy and autologous stem cell transplantation is often administered in such cases. This intensive intervention can be curative, but carries additional risks in the short and long term. This review includes a discussion of both transplant and non-transplant therapy for relapsed disease, commonly employed conditioning regimens, acute and late toxicities of therapy, as well as quality of life data. In addition, newer approaches to therapy for Hodgkin lymphoma are reviewed, with a focus on how such novel therapies might relate to high-dose chemotherapeutic approaches.

Keywords: Hodgkin lymphoma, adolescents, high-dose chemotherapy, autologous stem cell transplant

\section{Introduction}

Hodgkin lymphoma (HL) is one of the most common malignancies diagnosed in adolescents and young adults with an incidence of 1.2 cases per year per 100,000 persons less than 20 years of age. ${ }^{1}$ Most patients with HL are cured of their disease, with event-free survival (EFS) rates as high as $90 \%$ and $75 \%$ for early and advanced stage disease, respectively. ${ }^{2}$ Treatment usually includes multiple chemotherapeutic agents in combination with involved field radiation therapy (IFRT). With increasing cure rates, efforts to reduce the burden of therapy and late effects of treatment have become the focus of many new risk stratified treatment algorithms. ${ }^{3}$ For those with refractory or recurrent disease, cure is still possible, with differing approaches depending on time to progression, prior therapy, presence of B symptoms, and stage of disease. ${ }^{4-6}$ Despite risks of toxicity, therapy is typically intensified in the second-line setting because this is the last realistic chance for cure. ${ }^{4}$

High-dose chemotherapy (HDCT) and autologous stem cell transplantation (ASCT) are well-established as a salvage strategy for relapsed and refractory HL. ${ }^{4-7}$ While this approach is almost universally employed in adults with relapsed and refractory HL, there is debate as to which children and adolescents should be offered this strategy, and numerous different salvage and HDCT conditioning regimens have been studied. . $^{2,8}$ Treatment strategies for refractory/recurrent HL should be focused on optimizing the 
chance of cure with consideration of early and late toxicities, as well as quality of life.

\section{Non-transplant therapy for relapsed/refractory disease}

Large prospective therapy trials in children and adolescents with relapsed/refractory HL have not been possible due to the relative rarity of HL and the success of upfront therapies that cure the majority of patients. If only $10 \%-25 \%$ of patients with HL develop relapsed or progressive disease, using the aforementioned SEER data, only 1-3 cases per million persons less than 20 years of age will require salvage therapy each year. As such, there is a lack of good quality prospective scientific data in this population, and the majority of publications are single institution retrospective analyses or registry data.

Radiation therapeutic decisions are usually determined based upon relapse stage, whether or not radiation therapy (RT) was given with initial therapy, and if so, whether relapse occurred within the prior RT field. For example, a minority of patients with limited stage relapsed disease who did not have RT as a component of their upfront treatment may receive RT alone as salvage treatment. ${ }^{2,9,10}$

While HDCT is generally accepted as standard therapy following salvage chemotherapy in adults, for children and adolescents, standard dose chemotherapy (SDCT) is considered by some experts to have comparable efficacy to HDCT in select patients with less toxicity. ${ }^{2,4,8}$ Multiple different chemotherapeutic protocols have been described, and no randomized trial has established a superior choice of salvage agents (Table 1). Consideration of prior drug exposures to maximize the administration of new agents while avoiding cumulative toxicities is of importance. In addition to prior therapy received, the time to progression and response to salvage therapy have been identified to be important prognostic factors that might direct therapeutic decisions. , $7,8,16,24^{2}$

A retrospective analysis in Britain comparing conventional chemotherapy to HDCT and ASCT in children and adolescents with relapsed and refractory disease showed no survival advantage, except for those with primary refractory disease, in whom stem cell transplantation (SCT) was shown to be of benefit. ${ }^{8}$ This analysis has been criticized for the differences in the two groups which might account for the results - namely, that the HDCT group contained a greater proportion of subjects with adverse prognostic factors. ${ }^{25}$ Several other authors have published excellent salvage results with SDCT, typically in the setting of late and localized relapse. ${ }^{16,26,27}$ The adult literature demonstrates that SDCT was clearly inferior to HDCT, even for those adults who relapsed greater than 1 year from the end of initial therapy. ${ }^{5,11,28}$ These findings, coupled with reports from several authors stating that the adult literature for HL can be extrapolated to adolescents (who comprise the majority of subjects in a relatively sparse pediatric literature), conflict with data suggesting that SDCT can be used successfully to salvage select children and adolescents. ${ }^{2,29,30}$ Of note, a German report of salvage SDCT in children and young adults showed no difference in outcomes between those less than 15 years of age compared to those greater than 15 years. ${ }^{16}$

Table I Common salvage regimens for relapsed/refractory Hodgkin lymphoma

\begin{tabular}{|c|c|c|c|c|c|c|}
\hline Author, year & Chemotherapy & $\begin{array}{l}\text { Number of } \\
\text { subjects }\end{array}$ & $\begin{array}{l}\text { Age range } \\
\text { (years) }\end{array}$ & $\begin{array}{l}\text { ORR } \\
(\%)\end{array}$ & $\begin{array}{l}\text { CR } \\
\text { (\%) }\end{array}$ & $\begin{array}{l}\text { Toxic } \\
\text { deaths (\%) }\end{array}$ \\
\hline Schmitz 2002"I & Dexa-BEAM & 144 & $16-55$ & 81 & 27 & 5 \\
\hline Martin $200 \mathrm{I}^{12}$ & Mini-BEAM & 55 & $15-60$ & 84 & 51 & 2 \\
\hline Aparicio $1999^{13}$ & ESHAP & 22 & $>18$ & 73 & 41 & 5 \\
\hline Moskowitz 200 I 14 & ICE & 65 & $12-59$ & 88 & 26 & 0 \\
\hline Josting $2002^{15}$ & DHAP & 102 & $21-64$ & 89 & 21 & 0 \\
\hline Schellong $2005^{16}$ & IEP-ABVD & 176 & $4-24$ & 85 & NR & 0 \\
\hline Baetz $2003^{17}$ & GDP & 23 & $19-57$ & 69 & 17 & 0 \\
\hline Bonfante $\left.200\right|^{18}$ & VI & 47 & $20-N R$ & 83 & 45 & 0 \\
\hline Proctor $2003^{19}$ & IVE & 51 & $16-53$ & 84 & 60 & 0 \\
\hline Santoro $2007^{20}$ & IGEV & 91 & $17-59$ & 81 & 28 & 0 \\
\hline Ferme $2002^{21}$ & MINE & 157 & $15-65$ & 75 & NR & 5 \\
\hline Cole $2009^{22}$ & GV & 30 & $11-29$ & 76 & 20 & 0 \\
\hline Shafey $2012^{23}$ & DICEP & 73 & $19-55$ & 86 & 18 & I \\
\hline
\end{tabular}

Abbreviations: ORR, overall response rate; CR, complete response; Dexa-BEAM, dexamethasone, carmustine, etoposide, cytarabine, melphalan; Mini-BEAM, carmustine, etoposide, cytarabine, melphalan; ESHAP, etoposide, methylprednisolone, cytarabine, cisplatin; ICE, ifosfamide, carboplatin, etoposide; DHAP, dexamethasone, cytarabine, cisplatin; IEP-ABVD, ifosfamide, etoposide, prednisolone, doxorubicin, bleomycin, vinblastine, dacarbazine; NR, not reported; GDP, gemcitabine, dexamethasone, cisplatin; $\mathrm{VI}$, vinorelbine, ifosfamide; IVE, ifosfamide, etoposide, epirubicin; IGEV, ifosfamide, gemcitabine, vinorelbine, prednisolone; MINE, mitoguazone, ifosfamide, vinorelbine, etoposide; GV, gemcitabine, vinorelbine; DICEP, dose-intensified cyclophosphamide, etoposide, cisplatin. 
So which children and adolescents should be offered SDCT? Pediatric patients who have either progressive disease on upfront chemotherapy or relapse within 3 months of completion of initial treatment clearly benefit from HDCT and ASCT, and are often described to have primary refractory disease and assigned a high-risk stratification., ${ }^{2,8,16}$ SDCT alone is not recommended for this population. Those who relapse greater than 12 months after completion of initial treatment are described by European groups as having lowrisk disease, particularly those who only received two cycles of primary therapy at initial diagnosis. ${ }^{2,16}$ Schellong et al describe 10-year disease-free survival (DFS) and overall survival (OS) rates of $86 \%$ and $90 \%$ in those patients who relapsed greater than 1 year off therapy with SDCT and individualized RT. ${ }^{16}$ In this study, an intermediate-risk group was defined as those who relapsed 3-12 months from the end of initial therapy. The EuroNet trial in Europe (EuroNetPHL-C1) will incorporate staging at initial diagnosis and time to relapse/progression to define low-, intermediate-, and high-risk groups. ${ }^{2}$ Early response to treatment as determined by positron emission tomography (PET) will determine whether intermediate-risk relapsed subjects are assigned to receive standard or high-dose chemotherapy as consolidation.

Even if HDCT may be clearly indicated for a patient based on disease characteristics, not all patients are eligible for such intensive therapy due to comorbidities. It should also be noted that many patients live in countries where HDCT or particular SDCT agents may be cost-prohibitive. When such therapies are contraindicated or inaccessible, single-agent chemotherapy might be a consideration, as such agents have allowed for a period of disease control with acceptable toxicity. Extensive experience with agents such as gemcitabine, vinorelbine, and vinblastine has been described and is briefly summarized in Table $2 .{ }^{31-38}$ Such an approach might allow for prolongation of life with good quality with the possibility of prolonged remission.

\section{Review of current HDCT and ASCT approaches in the management of Hodgkin lymphoma in adolescents}

HDCT has been long established as a therapy for relapsed and refractory HL., ${ }^{4,6}$ Two adult randomized trials have demonstrated the benefit of HDCT and autologous SCT. ${ }^{11,28}$ It should be noted that the HD-R1 study included only subjects with chemosensitive disease, and that no such randomized trial has been performed in the pediatric population due to small numbers of patients with relapsed/refractory disease. ${ }^{2,11}$ A recent Cochrane Collaboration has shown a nonstatistically significant trend for improved OS using HDCT and ASCT compared to SDCT in a broader age range, with significant improvement in progression-free survival (PFS). ${ }^{39}$ Various different regimens exist, and the lack of high quality prospective data means there is no accepted standard of care for conditioning. ${ }^{4,6} \mathrm{HDCT}$ is ideally given after achieving at least some degree of disease response, and disease status at the time of HDCT has been shown to be prognostic. ${ }^{4-6}$ The role of PET in pediatric patients receiving salvage therapy is unknown at present, but is being studied in the EuroNet trial. ${ }^{2} \mathrm{PET}$ imaging prior to HDCT in the adult population has been studied more extensively; PET has been used to stratify therapy in one salvage study, and those having PET negative disease following first-line salvage therapy pre-HDCT had improved outcomes. ${ }^{4,24}$

\section{Conditioning regimens}

Various different HDCT regimens have been used prior to ASCT for relapsed and refractory HL. The two most commonly reported regimens are BEAM (carmustine, etoposide, cytarabine, and melphalan) and CBV (cyclophosphamide, carmustine, and etoposide), ${ }^{2,4,5}$ Table 3 describes the BEAM and $\mathrm{CBV}$ regimens in detail. ${ }^{7,11,40-42}$ One retrospective comparison of BEAM versus $\mathrm{CBV}$ conditioning showed a 5-year PFS of $92 \%$ for BEAM and $73 \%$ for CBV, with no statistically significant difference in OS. ${ }^{43}$ Differences between the groups

Table 2 Single agent salvage therapy for Hodgkin lymphoma

\begin{tabular}{|c|c|c|c|c|c|}
\hline Author, year & Agent & $\begin{array}{l}\text { Number of } \\
\text { subjects }\end{array}$ & ORR (\%) & CR (\%) & $\begin{array}{l}\text { Median OS } \\
\text { (months) }\end{array}$ \\
\hline Santoro $2000^{32}$ & Gemcitabine & 23 & 39 & 9 & 10.7 \\
\hline Venkatesh $2004^{33}$ & Gemcitabine & 29 & 22 & 0 & 26.9 \\
\hline Zinzani $2000^{34}$ & Gemcitabine & 14 & 43 & 14 & NR \\
\hline Aurer $2005^{35}$ & Gemcitabine & 14 & 64 & 43 & II \\
\hline Little $1998^{36}$ & Vinblastine & 17 & 59 & 12 & 38.8 \\
\hline Devizzi $1994^{37}$ & Vinorelbine & 24 & 50 & 14 & 11 \\
\hline Rule $1998^{38}$ & Vinorelbine & 8 & 50 & 0 & NR \\
\hline
\end{tabular}

Abbreviations: ORR, overall response rate; CR, complete response; OS, overall survival; NR, not reported. 
Table 3 BEAM and CBV conditioning regimens

\begin{tabular}{ll}
\hline & Total dose \\
\hline BEAM & \\
Carmustine & $300 \mathrm{mg} / \mathrm{m}^{2}$ \\
Etoposide & $800-1,600 \mathrm{mg} / \mathrm{m}^{2}$ \\
Cytarabine & $800-1,600 \mathrm{mg} / \mathrm{m}^{2}$ \\
Melphalan & $140 \mathrm{mg} / \mathrm{m}^{2}$ \\
CBV & \\
Cyclophosphamide & $3,000-7,200 \mathrm{mg} / \mathrm{m}^{2}$ \\
Carmustine & $300-450 \mathrm{mg} / \mathrm{m}^{2}$ \\
Etoposide & $1,800-2,400 \mathrm{mg} / \mathrm{m}^{2}$ \\
\hline
\end{tabular}

Note: Data from various sources. $7,11,40-42$

Abbreviations: BEAM, carmustine, etoposide, cytarabine, and melphalan; CBV, cyclophosphamide, carmustine, and etoposide.

other than conditioning may have accounted for the superior outcomes seen with BEAM. ${ }^{4,43}$ Total body irradiation-based regimens have been used historically, but concerns regarding radiation toxicity have resulted in a shift to non-radiationbased conditioning. ${ }^{2,5}$ Other multi-agent-conditioning regimens showing promise include gemcitabine, busulfan, and melphalan, which compared favorably to BEAM and busulfan/melphalan in a single institution study. ${ }^{42}$ Bains et al have published favorable retrospective results with busulfan, melphalan, and thiotepa. ${ }^{44}$ Single-agent, high-dose melphalan has also been used with success. ${ }^{45,46}$ The EFS and OS rates in these publications are comparable to other published reports, and a randomized trial, if feasible, would best answer a question regarding superiority of a given combination of conditioning agents.

\section{Efficacy of HDCT in relapsed and refractory $\mathrm{HL}$}

Reports of PFS after HDCT chemotherapy have ranged from $31 \%-67 \%$ for relapsed/refractory HL in children and adolescents (Table 4). 5,7,8,30,40,41,47-49 OS has varied between $43 \%$ and $95 \%$, with adult series describing OS between
$30 \%$ and $65 \% .^{6,7,47}$ The duration of follow-up is important to note when reviewing the literature - while most patients relapse within 2 years of diagnosis, later relapses have been described post-HDCT and 38\% of deaths in one series occurred between 4 and 12 years post-ASCT. ${ }^{7,47}$

Results of HDCT and ASCT in children and adolescents (typically grouped together) are generally small case series with variability in the therapy given prior to HDCT. While subject numbers in pediatric publications are often relatively small compared to adult series, some authors have shown comparable results for HDCT and ASCT in children and adults. ${ }^{30}$ Notably, in a paper by Baker et al, while including subjects aged 21 years and younger, only six of these were aged $<13$ years, meaning this analysis was primarily one of adolescents, with further analyses performed for those 13-18 and 19-21 years of age. ${ }^{47}$ The PFS and OS were compared to a cohort $>21$ years of age, with very similar results. Williams et al described similar findings when comparing pediatric and adult data with pediatric subjects case matched with adult subjects (although the older age range was $16-50$ years). ${ }^{30}$ While the best results in the pediatric literature were from Spain, with an EFS of $62 \%$ and an OS of $95 \%$, this series included few cases of primary refractory HL and these outcomes have not been replicated elsewhere. ${ }^{48}$ Many of these children and adolescents received CBV conditioning (55\%). Outcomes specifically for primary refractory disease have been worse, and such cases comprise $10 \%-30 \%$ of subjects in various analyses with progressionand failure-free survival rates between $9 \%$ and $38 \%$. ${ }^{7,8,30,47,48,50}$ Data specific for adolescents is scarce, and such data is often combined with pediatric outcomes or extrapolated from adult series. One of the few publications describing exclusively adolescent outcomes cites an EFS and OS of $45 \%$ and $55 \%$, respectively. ${ }^{40}$ The adolescents treated in this series

Table 4 Outcomes after HDCT and ASCT for children and adolescents

\begin{tabular}{|c|c|c|c|c|c|c|}
\hline Author, year & $\begin{array}{l}\text { Number of } \\
\text { subjects }\end{array}$ & $\begin{array}{l}\text { Age at HDCT } \\
\text { (years) }\end{array}$ & Conditioning & Response (\%) & OS (\%) & $\begin{array}{l}\text { Median follow-up } \\
\text { (months) }\end{array}$ \\
\hline Williams $1993^{30}$ & 81 & $3-16$ & Variable & PFS 39 & 64 & 36 \\
\hline Baker $1999^{47}$ & 53 & $<2$ I & Variable, 44/53 CBV & FFS 3I (5-year) & 43 (5-year) & 65 \\
\hline Verdeguer $2000^{48}$ & 20 & $5-18$ & $\begin{array}{l}\text { Variable, II/20 CBV } \\
\text { 5/20 BEAM }\end{array}$ & EFS 62 (5-year) & 95 (5-year) & 40 \\
\hline Stoneham $2004^{8, *}$ & 51 & $3-16$ & Variable, 44/5I BEAM & DFS 67 & 71 & 54 \\
\hline Lieskovsky $2004^{7}$ & 41 & $7-20$ & $\begin{array}{l}\text { Variable, } 23 / 4 \text { I CBV } \\
\text { 6/4I TBI-based }\end{array}$ & $\begin{array}{l}\text { EFS } 53 \text { (actuarial 5-year) } \\
\text { PFS } 63 \text { (5-year) }\end{array}$ & 68 (5-year) & 50 \\
\hline Harris $20 \mathrm{II}^{4 \mathrm{I}}$ & 28 & $<2$ I & CBV & EFS 65 (3-year) & 64 (3-year) & 38 \\
\hline Akhtar $2010^{40}$ & 58 & $|4-2|$ & BEAM & EFS 45 (actuarial II-year) & 55 (actuarial I I-year) & 43 \\
\hline
\end{tabular}

Note: $* 2$ deaths from unrelated causes.

Abbreviations: HDCT, high-dose chemotherapy; ASCT, autologous stem cell transplantation; OS, overall survival; PFS, progression-free survival; FFS, failure-free survival; CBV, cyclophosphamide, carmustine, etoposide; EFS, event-free survival; BEAM, carmustine, etoposide, cytarabine, melphalan; DFS, disease-free survival; TBI, total-body irradiation. 
received ESHAP (etoposide, methylprednisolone, cisplatin, and cytarabine) as first-line salvage in $88 \%$ of cases, and all subjects were conditioned with BEAM. The presence of B-symptoms at the time of relapse or progression was found to be a negative prognostic factor. A total of 58 adolescents were described with $53 \%$ in complete remission (CR) a median of 43 months post-ASCT. Of the 22 subjects who died (38\%), 21 died of disease with the remaining subject sustaining accidental death. Disease status at the time of HDCT was prognostic in the multivariate analysis with 93\% EFS for those with $\mathrm{CR} /$ complete response undetermined $(\mathrm{CRu})$ compared to $30 \%$ for those with either a partial response (PR), stable disease (SD), or no response (NR).

Other adverse prognostic features predicting outcome post-HDCT and-ASCT include the time to recurrence, the presence of extranodal disease, stage at initial diagnosis, large residual mediastinal mass pre-HDCT, and an elevated $\mathrm{LDH}$ before HDCT. ${ }^{2,5,7,40,49,51}$ Those with chemotherapy-resistant disease prior to HDC have $<10 \%$ chance of cure. ${ }^{5,47}$ While numerous prognostic variables have been published for children and adolescents, there is no reproducible and universally agreed upon model for their application in patients in this age group. ${ }^{2}$ There is no evidence that age at the time of HDCT and ASCT is an independent variable influencing outcome, nor that the biology of HL differs between age groups. ${ }^{5}$

\section{Tandem HDCT and ASCT}

Several investigators have published outcomes of sequential HDCT followed by ASCT as well as tandem ASCT.4,23,39,45,52 While sequential HDCT and ASCT has not been shown to be a superior approach, for those patients with particularly poor prognoses, Devillier et al describe $43 \%$ PFS at 5 years for those subjects who were PET positive prior to tandem ASCT compared to $0 \%$ for those with positive PET scans prior to single ASCT. ${ }^{53}$ PET status prior to ASCT was the most predictive prognostic factor in this analysis.

Additionally, five Phase II studies have investigated the role of tandem ASCT for relapsed and refractory HL. ${ }^{4}$ The largest of these studies showed a freedom-from-failure survival (FFS) and OS of $40 \%$ and $47 \%$, respectively for the poorest-risk subjects who underwent tandem HSCT. ${ }^{54,55}$ Such subjects had either primary refractory disease or multiple unfavorable risk factors, and these results compare favorably to historical data for those with similar disease characteristics. However, while some of the aforementioned publications suggest that tandem HSCT may provide benefit to poor-risk patients, the sum of data that exist does not support the routine practice of tandem HSCT for relapsed/refractory HL.

\section{Acute toxicities of HDCT}

Treatment-related mortality (TRM) following HDCT and ASCT for HL has historically been a significant concern. TRM has been reported as high as $26 \%$ using CBV conditioning, with or without cisplatin. ${ }^{56}$ The TRM rate dropped to $14 \%$ in this series when second malignancies were excluded. Similarly, Baker et al described 17\% TRM in children and adolescents who underwent HDCT, many of whom received $\mathrm{CBV}^{47}$ The Stanford experience from 1989-1998 reported that five of 34 children (15\%) died post-HDCT for HL, most of whom had a lethal pulmonary complication. ${ }^{49}$ European registry data for 81 pediatric patients documented an $11 \%$ TRM rate, with all patients undergoing HDCT before $1993 .{ }^{30}$ When current supportive care measures are employed, many experts believe the TRM associated with HDCT for HL is closer to $5 \% .^{10,11,14,50,57}$

Patient screening for comorbidities and baseline endorgan function is also of importance. Many centers require baseline pulmonary, cardiac, hepatic, and renal parameters to be met for a patient to be eligible for HDCT. Granulocyte colony-stimulating-factor is routinely administered to promote neutrophil recovery, as grade 4 hematopoietic toxicity is expected with myeloablative conditioning.

Pulmonary complications remain a significant concern post-HDCT and-ASCT. Numerous authors have published notable rates of pulmonary morbidities which can lead to mortality (Table 5). ${ }^{7,10,11,30,41,49,56,57}$ Rates of toxicity between $21 \%$ and $39 \%$ have been reported with carmustine- or lomustine-based conditioning. Frankovich et al reported an interesting association between a prior history of atopy and non-infectious pneumonitis. ${ }^{49}$ The authors postulate Th2 cytokine signaling common to both asthma/atopy and HL as a possible mechanism of injury. The Children's Oncology Group demonstrated a dose effect of carmustineassociated pulmonary toxicity on the relapsed/refractory pediatric lymphoma study A5962, with all 6/6 subjects who received $450 \mathrm{mg} / \mathrm{m}^{2}$ of carmustine developing grade 3 or 4 pulmonary toxicity, typically $30-60$ days post-ASCT. ${ }^{41}$ In contrast, none of the 32 subjects who received $300 \mathrm{mg} / \mathrm{m}^{2}$ of carmustine developed grade 3 or greater pulmonary toxicity. It should be noted that while outcomes for nonHodgkin lymphoma (NHL) and HL were sub-analyzed, the pulmonary toxicity was reported in aggregate for all NHL and HL subjects. Stewart et al propose that conditioning agents known to increase the risk of lung toxicity should be avoided, and that even single-agent melphalan (with reduced pulmonary risk) can be used safely without compromising efficacy. ${ }^{45,46,58}$ 
Table 5 Pulmonary toxicities with HDCT

\begin{tabular}{|c|c|c|c|}
\hline Author, year & $\begin{array}{l}\text { Total number } \\
\text { of subjects }\end{array}$ & Rate of pulmonary toxicity & Notes \\
\hline \multirow[t]{2}{*}{ Williams $1993^{30}$} & 81 children & $6 / 81(7 \%)$ & Interstitial pneumonia \\
\hline & & & All 6 died \\
\hline \multirow[t]{5}{*}{ Frankovich $200 I^{49}$} & 34 children & I5/34 (44\%) & Toxicity described as post-ASCT idiopathic diffuse \\
\hline & & & lung injury syndrome \\
\hline & & & 5 deaths due to pulmonary toxicity \\
\hline & & & $80 \%$ of those with idiopathic lung complications had \\
\hline & & & a history of atopy \\
\hline \multirow[t]{4}{*}{ Lieskovsky $2004^{7}$} & 41 children & $16 / 4 \mid(39 \%)$ & Larger Stanford experience which includes those \\
\hline & & & described by Frankovich \\
\hline & & & Post-ASCT idiopathic diffuse lung injury syndrome \\
\hline & & & Most patients received carmustine or lomustine \\
\hline \multirow[t]{3}{*}{ Lavoie $2005^{10}$} & 100 (ages I6-52) & $24 \%$ with $600 \mathrm{mg} / \mathrm{m}^{2}$ carmustine (CBV & 9 deaths due to pulmonary toxicity, 6 beyond \\
\hline & & regimen) & day +100 \\
\hline & & $\begin{array}{l}21 \% \text { with } 500 \mathrm{mg} / \mathrm{m}^{2} \text { carmustine (CBV + } \\
\text { cisplatin regimen) }\end{array}$ & \\
\hline \multirow[t]{2}{*}{ Harris $20 \mathrm{II}^{4 \mathrm{I}}$} & 69 children & $6 / 6(100 \%)$ dosed at $450 \mathrm{mg} / \mathrm{m}^{2}$ carmustine & $\begin{array}{l}\text { All } 6 \text { had grade } 3 / 4 \text { pulmonary toxicity, typically } \\
\text { day }+30-60\end{array}$ \\
\hline & & $0 / 32(0 \%)$ dosed at $300 \mathrm{mg} / \mathrm{m}^{2}$ carmustine & Analysis of pulmonary toxicity includes $\mathrm{NHL}$ and $\mathrm{HL}$ \\
\hline
\end{tabular}

Abbreviations: HDCT, high dose chemotherapy; ASCT, autologous stem cell transplantation; CBV, cyclophosphamide, carmustine, etoposide; NHL, non-Hodgkin lymphoma; HL, Hodgkin lymphoma.

Invasive infections remain a concern post-HDCT for HL despite ASCT, and newer data describing immune reconstitution post-ASCT provide some insight as to the impact of such therapy on functional immunity in addition to myelosuppression. ${ }^{59}$ Septic deaths, while rare, can still occur post-ASCT, even beyond day $100 .^{7,11,57}$ The European registry data pre1993 included 81 children and adolescents, five of whom developed an invasive fungal infection. ${ }^{30}$

Other complications commonly seen post-myeloablative HDCT include mucositis and sinusoidal obstructive syndrome (SOS). SOS was reported in 5/81 subjects in the study by Williams et al, with comparable rates reported in children undergoing HDCT and ASCT for other diseases. ${ }^{30,60,61}$

\section{Long-term toxicities of HDCT and ASCT}

Late effects of therapy for HL remain a major concern both when considering initial therapy as well as treatment for relapsed and refractory disease. Efforts to maintain efficacy of therapy while mitigating life-limiting and life-threatening long-term complications of therapy are a key component to ongoing HL research.

Late mortality for patients with HL is a significant consideration, and secondary malignancies (SM) are a major contributor to late mortality. ${ }^{62}$ Rates of SM have varied in the literature between $8 \%$ and $15 \% .{ }^{62-64}$ Treatmentrelated myelodysplastic syndrome/acute myeloid leukemia (t-MDS/t-AML) are associated with alkylating agent and podophyllotoxin exposure and have high rates of mortality. Given that many HDCT regimens include agents known to be associated with t-MDS/t-AML, investigators have questioned the additional risk of HDCT to the baseline risk of SM in patients treated for HL. There is no conclusive evidence that HDCT adds any additional risk of developing t-MDS/t-AML compared to conventional chemotherapy for HL. ${ }^{62-65}$ While a French series showed a higher rate of solid tumors post-HDCT, this finding was not seen in a British Columbia cohort. ${ }^{63,64}$

Late mortality is increased in those who have undergone HDCT and ASCT compared to those who have received SDCT/RT for HL. ${ }^{63}$ The British Columbia experience showed a 15 -year probability of death of $14 \%$ for those who received conventional treatment and $43 \%$ for those who received HDCT, although it should be noted that while pediatric and adolescent patients were included in the analysis, this was primarily an adult series.

Cardiac and pulmonary late effects post-therapy for HL are of particular concern. Those who have received HDCT are also at high risk for such complications, and the Bone Marrow Transplant Survivor Study showed a cause-specific standardized mortality ratio of 29.1 for death due to pulmonary disease for those who received HDCT. ${ }^{66}$ Higher late non-relapse mortality was noted for those patients who received carmustine.

Fertility preservation remains a priority for adolescents and young adults undergoing cancer therapy. Primary therapy 
for HL can compromise fertility, particularly due to exposure to alkylating agents, and cause premature menopause, and some males may have primary gonadal dysfunction at diagnosis. ${ }^{67,68} \mathrm{HDCT}$ is associated with high rates of infertility ${ }^{69}$ While there has been an increased awareness of the importance of onco-fertility conversations and options over recent years, the quality of such discussions and access to such services remain inadequate in many cases. ${ }^{67,70,71}$ Conversations regarding fertility preservation options should ideally take place before therapy is initiated, and include a review of those options considered standard of care. ${ }^{67,72,73}$ The state of the science and standards of care are continually in evolution; ${ }^{50}$ referral to a service with specific expertise in onco-fertility should be considered to allow for adolescents to access or decline all appropriate options, as well as taking into account any available research studies.

\section{Quality of life issues}

In addition to short- and long-term medical complications of therapy, additional quality of life (QOL) issues are pertinent to adolescents who are receiving or have received therapy for HL. Data specific to survivors of HL who have undergone HDCT and ASCT suggest that two-thirds in a Stanford cohort had no limitations on their health. ${ }^{62}$ While global QOL was similar between those who underwent HDCT for HL and the general population, the group who underwent therapy reported decreased social and cognitive functioning, while increased rates of financial difficulties, insomnia, fatigue, and dyspnea were noted. It should be stated that the group who underwent HDCT was not compared to a group who received conventional chemotherapy, but rather a healthy reference population. Bhatia et al studied survivors of the Minnesota and City of Hope programs and found marital rates were similar for survivors and the sibling comparison group. ${ }^{66}$ Survivors post-HDCT and -ASCT had more difficulty maintaining employment related to a health issue compared to siblings ( $15 \%$ versus $2 \%$ ), and older participants in the study had more difficulty with employment than did those who were younger. While most survivors had health insurance (at comparable rates to their siblings), participants aged 45 years or younger had more difficulty obtaining or maintaining health or life insurance compared to siblings.

The Memorial Sloan Kettering group studied QOL in a cohort of HL survivors who underwent HDCT and ASCT and found that the number of recurrences was significantly associated with reduced QOL functional scores and a higher pain score. ${ }^{74}$ A German study of long-term survivors of HL published in 2010 specifically compared those who underwent HDCT and conventional chemotherapy. ${ }^{75}$ While there was a trend towards decreased QOL in the three major domains of a European standard tool for QOL measurement, aside from more dyspnea in the HDCT group, these differences did not achieve statistical significance. Those subjects who received carmustine as part of their HDCT regimen were more likely to report dyspnea - a relevant finding given that BEAM and CBV are commonly used HDCT protocols. The HDCT group did report significantly decreased QOL in the subcategories of physical, role, emotional, cognitive, and social functioning as well as fatigue, dyspnea, insomnia, diarrhea, and financial difficulties when compared to a healthy reference population. Another recent German paper showed no impact of intensity of conventional chemotherapy on sexual functioning post-therapy for $\mathrm{HL}$, but no subjects in this analysis received HDCT and those with more advanced disease had more difficulties. ${ }^{76}$

\section{Radiation post-HDCT}

The practice of adding RT either pre- or post-HDCT andASCT is based on the evidence supporting the benefit of RT in the setting of combination therapy for advanced stage HL. ${ }^{77}$ It should be noted, however, that similar to much of the data supporting the use of HDCT in the setting of relapsed and refractory $\mathrm{HL}$, the data regarding the use of RT with salvage HDCT is retrospective and often consists of the experience of a single institution. ${ }^{78}$ No randomized trials exist and due to the rarity of patients, the age ranges are broad. ${ }^{77,79-82}$ Most of these studies involve heterogenous populations in terms of indication for RT, dose, timing, and choice of field. ${ }^{78}$ In addition, these data typically do not exclude radiation-naïve subjects. ${ }^{77,80-82}$

Data from Emory University from Kahn et al described a cohort in which none had received prior RT. ${ }^{79}$ DFS was improved in those subjects who received IFRT with bulk disease. Common sites of failure remain within the radiation field and prior sites of disease bulk. A trend towards benefit for those who received IFRT without bulk disease was noted, but small numbers may have precluded statistical significance. Pulmonary and neurotoxicity were noteworthy for some subjects who received busulfan as part of their HDCT regimen.

The Stanford experience in 100 consecutive patients who underwent HDCT for HL included 24 patients who received IFRT, typically for cytoreduction prior to HDCT. ${ }^{77}$ Improved freedom-from-relapse (FFR) was noted for those who had not received prior RT with disease stages I-III. Mundt et al describe a cohort of 54 patients, 20 of whom received IFRT 
either before (7) or after (13) HDCT. ${ }^{82}$ Those subjects who had persistent disease post-HDCT benefited from IFRT, and those who converted to a CR using IFRT post-HDCT had comparable outcomes to those who achieved a CR with HDCT alone. Other authors have published additional data both supporting and refuting the benefit of IFRT for those patients undergoing HDCT. ${ }^{57,77,83}$

Patients who relapse post-HDCT and -ASCT may also benefit from RT. Case reports describe rare patients who have sustained long-term remissions with RT alone. ${ }^{82}$ Even for those patients who receive RT with palliative intent, RT can allow for good disease control for a sustained period of time with acceptable toxicity. ${ }^{84}$

In summary, the use of IFRT in conjunction with HDCT and ASCT has produced variable results. ${ }^{78,80}$ The data are conflicting, retrospective, and non-randomized in nature with bias in the selection of patients who receive IFRT (typically those with bulky or persistent disease, which are known adverse risk factors). ${ }^{80}$ As such, these studies are difficult to compare directly. Based on the data that exist, in any case, select patients should be considered for RT around the time of HDCT given that most recurrences post-HDCT are in sites known to have been involved prior to HDCT, IFRT can achieve local control in many cases of HL, and IFRT is a well-established component of combined-modality therapy. ${ }^{77}$ Considering the aforementioned data suggesting that patients with persistent disease post-HDCT derive benefit from IFRT, and data suggesting that rates of radiation pneumonitis are lower for those who receive mediastinal RT post-HDCT, a reasonable approach would be to routinely offer IFRT to those who are not in $\mathrm{CR}$ after HDCT following recovery post-ASCT. ${ }^{85}$

\section{Future directions}

Outcomes for patients who relapse after HDCT and ASCT are typically poor. ${ }^{4}$ Therapeutic options for this group have typically been experimental therapies or allogeneic SCT. Published allogeneic SCT conditioning regimens have included myeloablative and reduced intensity approaches. While myeloablative conditioning has been associated with lower relapse rates, TRM is quite high in this population of heavily pre-treated patients. With lower rates of TRM using reduced intensity conditioning approaches, many patients who undergo allogeneic SCT receive reduced intensity preparative regimens. The goal of reduced intensity regimens is to avail of a graft-versus-lymphoma effect for disease control. While some authors equate relapse or progression post-HDCT and -ASCT ultimately with death, there appears to be a subset of patients which can benefit from allogeneic SCT. ${ }^{4,86}$ Adolescent patients can typically tolerate such intensive therapies more readily than older patients.

The largest study to date exploring outcomes of patients who relapsed or progressed post-HDCT and-ASCT is a retrospective analysis from Greece, which identified risk factors that can help predict which patients might benefit the most from attempts at salvage therapy post-HDCT and -ASCT. ${ }^{86}$ Those patients who relapsed or progressed within 1 year post-ASCT, those with B symptoms at relapse/ progression, and those with refractory disease pre-initial HDCT and ASCT fared the worst. The results of this analysis were surprisingly favorable for a population with a historically dismal prognosis. Most patients had received BEAM conditioning prior to their initial ASCT. With a median follow-up of 32 months, 53 of 126 patients were alive, with 44 being free of disease progression. Fourteen patients underwent allogeneic SCT.

Since relapse post-HDCT and-ASCT remains the most common cause of death, and keeping in mind the late toxicities of the many modalities of therapy for HL, novel therapies which target the interactions of Hodgkin and Reed Sternberg cells and their complex microenvironment are the focus of new and innovative treatments for relapsed disease. ${ }^{87}$ Combined with biomarkers to add to existing prognostic factors, such therapies are being studied in those patients with the most aggressive disease biology, and agents which show promise are then incorporated into front-line and salvage strategies for future study. A multitude of agents have and continue to be investigated in Phase I and II settings, but given the rarity of HL and the relatively small proportion of patients who fail upfront therapy, only agents with the most promise are prioritized in order to develop quality studies powered to provide data which can truly inform widespread practice.

Brentuximab vedotin (BV) is an antibody-drug conjugate that targets the CD30 receptor, and has demonstrated significant efficacy in a population of subjects with highly resistant HL. ${ }^{87,88}$ The results of a Phase II study demonstrated impressive efficacy with acceptable toxicity. ${ }^{89}$ The median age of those enrolled was 31 years, with some subjects in the adolescent age range. All subjects had relapsed or progressed post-HDCT and -ASCT. Of the 102 subjects, 75\% had an overall response, with 34\% achieving CR. The PFS for this cohort was $30 \%$ with a median follow-up of 1.5 years posttherapy. Responses were durable for a median of 2 years in those who achieved a CR. Another Phase II study of transplant-naïve subjects showed a $71 \%$ overall response 
rate, with $36 \%$ of subjects achieving CR.${ }^{90}$ In this study, $5 / 9$ of these transplant-naïve patients with refractory disease subsequently became eligible for HDCT following exposure to $\mathrm{BV}$, with an overall PFS of $28 \%$ at 1 year.

Side effects of BV include peripheral neuropathy (generally reversible), nausea, and fatigue. ${ }^{88}$ Given the acceptable toxicity profile of this agent, particularly in comparison to intensive interventions such as allogeneic $\mathrm{SCT}$, the role of consolidation with an allograft after exposure to this agent is called into question. It should be noted that the durability of responses requires further study, but to date, the experience with re-exposure to $\mathrm{BV}$ is promising.

The impressive efficacy of BV has prompted its study in other patient populations. A study of its role in consolidation following HDCT and ASCT in subjects at increased risk of relapse is currently underway. ${ }^{88}$ The agent has also been integrated into standard chemotherapy regimens, with significant pulmonary toxicity noted when used in combination with bleomycin. ${ }^{87} \mathrm{~A}$ randomized trial comparing ABVD (doxorubicin, bleomycin, vinblastine, and dacarbazine) and $\mathrm{AVD}+\mathrm{BV}$ is underway, as is a trial for those with relapsed and refractory HL using sequential BV and ICE (ifosfamide, carboplatin, and etoposide) in transplant eligible subjects. ${ }^{87}$

Bendamustine is an alkylating agent with some mechanistic differences from more established alkylators, and has shown efficacy in subjects who have relapsed post-SCT (overall response rate [ORR]: 58\%, CR rate: 31\%, PFS: $21 \%$ at 2 years). ${ }^{91}$ Other agents have also shown promise, but given the success of BV, the future study of some of these agents is unlikely. Rituximab, an anti-CD20 molecule, showed promising efficacy when combined with ABVD in newly diagnosed subjects (ORR: 98\%, CR/CRu rate: 93\%, EFS: $83 \%$ at 5 years). ${ }^{92} \mathrm{~A}$ monoclonal antibody against PDI (an important $\mathrm{T}$ cell signaling molecule) is under study in a Phase I trial for relapsed hematological malignancies. ${ }^{87}$ Evaluation of the mammalian target of rapamycin (mTOR) inhibitor everolimus combined with the histone deacetylase (HDAC) inhibitor panobinostat has showed some encouraging results in a Phase I setting (ORR: 50\%). ${ }^{87}$ Phase I research involving phosphokinase cell signaling inhibition is ongoing.

\section{Conclusion}

The majority of adolescents diagnosed with HL are cured of their disease with upfront therapy, typically with SDCT with or without RT. For the $10 \%-20 \%$ of patients who have relapsed or refractory disease, many are offered salvage chemotherapy followed by HDCT and ASCT. The role of SDCT compared to HDCT and ASCT in children and adolescents remains an area of research interest. For those adolescents who undergo HDCT and ASCT, between 30\% and $70 \%$ are cured of their disease. Salvage following relapse or progression post-HDCT and-ASCT is difficult, although newer treatment modalities are showing promise. Late effects for all adolescents remain a major concern, and HDCT adds additional risks of long-term morbidity and mortality. Quality of life research in this population provides further insight into the impact of these morbidities. Newer agents such as brentuximab vedotin show promise both in terms of efficacy and toxicity profile, and are being studied in conjunction with HDCT and ASCT in an effort to consolidate responses to HDCT, as a bridge to HDCT and ASCT in combination with salvage chemotherapy, and increasingly as a component of upfront therapy to reduce the number of adolescents who ultimately require HDCT and ASCT. Risk stratification so as to intensify therapy for those at higher risk of relapse or progression is the focus of ongoing studies, ideally with the incorporation of biologic markers to improve accuracy.

\section{Disclosure}

The authors report no conflicts of interest in this work.

\section{References}

1. Seer.cancer.gov [homepage on the Internet]. Bethesda, MD: National Cancer Institute Surveillance, Epidemiology, and End Results Program; c2013-c2014 [updated December 31, 2013; cited January 16, 2014]. Available at: http://seer.cancer.gov/. Accessed January 16, 2014.

2. Daw S, Wynn R, Wallace H. Management of relapsed and refractory classical Hodgkin lymphoma in children and adolescents. $\mathrm{Br} J$ Haematol. 2010;152(3):249-260.

3. Hodgson DC, Hudson MM, Constine LS. Pediatric Hodgkin lymphoma: maximizing efficacy and minimizing toxicity. Semin Radiat Oncol. 2007;17(3):230-242.

4. Hertzberg M. Relapsed/refractory Hodgkin lymphoma: what is the best salvage therapy and do we need RIC-alloSCT? Hematol Oncol Clin North Am. 2014;28(1):123-147.

5. Claviez A, Sureda A, Schmitz N. Haematopoietic SCT for children and adolescents with relapsed and refractory Hodgkin's lymphoma. Bone Marrow Transplant. 2008;42 Suppl 2:S16-S24.

6. Kuruvilla J, Keating A, Crump M. How I treat relapsed and refractory Hodgkin lymphoma. Blood. 2011;117(16):4208-4217.

7. Lieskovsky YE, Donaldson SS, Torres MA, et al. High-dose therapy and autologous hematopoietic stem-cell transplantation for recurrent or refractory pediatric Hodgkin's disease: results and prognostic indices. J Clin Oncol. 2004;22(22):4532-4540.

8. Stoneham S, Ashley S, Pinkerton CR, Wallace WH, Shankar AG. Outcome after autologous hemopoietic stem cell transplantation in relapsed or refractory childhood Hodgkin disease. J Pediatr Hematol Oncol. 2004;26(11):740-745.

9. Roach M III, Kapp DS, Rosenberg SA, Hoppe RT. Radiotherapy with curative intent: an option in selected patients relapsing after chemotherapy for advanced Hodgkin's disease. J Clin Oncol. 1987;5(4): $550-555$.

10. Lavoie JC, Connors JM, Phillips GL, et al. High-dose chemotherapy and autologous stem cell transplantation for primary refractory Hodgkin lymphoma: long-term outcome in the first 100 patients treated in Vancouver. Blood. 2005;106(4):1473-1478. 
11. Schmitz N, Pfistner B, Sextro M, et al. Aggressive conventional chemotherapy compared with high-dose chemotherapy with autologous haematopoietic stem-cell transplantation for relapsed chemosensitive Hodgkin's disease: a randomised trial. Lancet. 2002;359(9323): 2065-2071.

12. Martin A, Fernandez-Jimenez MC, Caballero MD, et al. Long-term follow-up in patients treated with Mini-BEAM as salvage therapy for relapsed or refractory Hodgkin's disease. Br J Haematol. 2001;113(1): 161-171.

13. Aparicio J, Segura A, Garcera S, et al. ESHAP is an effective regimen for relapsing Hodgkin's disease. Ann Oncol. 1999;10(5):593-595.

14. Moskowitz CH, Nimer SD, Zelenetz AD, et al. A 2-step comprehensive high-dose chemoradiotherapy second-line program for relapsed and refractory Hodgkin disease: analysis by intent to treat and development of a prognostic model. Blood. 2001;97(3):616-623.

15. Josting A, Rudolph C, Reiser M, et al. Time-intensified dexamethasone/ cisplatin/cytarabine: an effective salvage therapy with low toxicity in patients with relapsed and refractory Hodgkin's disease. Ann Oncol. 2002;13(10):1628-1635.

16. Schellong G, Dörffel W, Claviez A. Salvage therapy of progressive and recurrent Hodgkin's disease: results from a multicenter study of the Pediatric DAL/GPOH-HD Study Group. J Clin Oncol. 2005;23(25): 6181-6189.

17. Baetz T, Belch A, Couban S, et al. Gemcitabine, dexamethasone and cisplatin is an active and non-toxic chemotherapy regimen in relapsed or refractory Hodgkin's disease: a phase II study by the National Cancer Institute of Canada Clinical Trials Group. Ann Oncol. 2003;14(12): $1762-1767$.

18. Bonfante V, Viviani S, Devizzi L, et al. High-dose ifosfamide and vinorelbine as salvage therapy for relapsed or refractory Hodgkin's disease. Eur J Haematol Suppl. 2001;64:51-55.

19. Proctor SJ, Jackson GH, Lennard A, et al. Strategic approach to the management of Hodgkin's disease incorporating salvage therapy with high-dose ifosfamide, etoposide and epirubicin: a Northern Region Lymphoma Group study (UK). Ann Oncol. 2003;14(Suppl 1): i47-i50.

20. Santoro A, Magagnoli M, Spina M, et al. Ifosfamide, gemcitabine, and vinorelbine: a new induction regimen for refractory and relapsed Hodgkin's lymphoma. Haematologica. 2007;92(1):35-41.

21. Ferme C, Mounier N, Divine $M$, et al. Intensive salvage therapy with high-dose chemotherapy for patients with advanced Hodgkin's disease in relapse or failure after initial chemotherapy: results of the Groupe d'Etudes des Lymphomes de 1'Adulte H89 Trial. J Clin Oncol. 2002;20(2):467-475.

22. Cole PD, Schwartz CL, Drachtman RA, et al. Phase II study of weekly gemcitabine and vinorelbine for children with recurrent or refractory Hodgkin's disease: a Children's Oncology Group Report. J Clin Oncol. 2009;27(9):1456-1461.

23. Shafey M, Duan Q, Russell J, et al. Double high-dose therapy with dose-intensive cyclophosphamide, etoposide, cisplatin (DICEP) followed by high-dose melphalan and autologous stem cell transplantation for relapsed/refractory Hodgkin lymphoma. Leuk Lymphoma. 2012;53(4):596-602.

24. Moskowitz CH, Matasar MJ, Zelenetz AD, et al. Normalization of preASCT, FDG-PET imaging with second-line, non-cross-resistant, chemotherapy programs improves event-free survival in patients with relapsed Hodgkin lymphoma. Leuk Lymphoma. 2011;52(9):1668-1674.

25. Galvão de Castro C Jr, Gregianin LJ, Brunetto AL. Autologous hematopoietic stem cell transplantation in children with relapse or refractory Hodgkin disease. J Pediatri Hematol Oncol. 2006;28(11):772.

26. Shankar AG, Ashley S, Radford M, Barrett A, Wright D, Pinkerton CR. Does histology influence outcome in childhood Hodgkin's disease? Results from the United Kingdom Children's Cancer Study Group. J Clin Oncol. 1997;15(7):2622-2630.

27. James ND, Kingston JE, Plowman PN, et al. Outcome of children with resistant and relapsed Hodgkin's disease. Br J Cancer. 1992;66(6): 1155-1158.
28. Linch DC, Winfield D, Goldstone AH, et al. Dose intensification with autologous bone-marrow transplantation in relapsed and resistant Hodgkin's disease: results of a BNLI randomised trial. Lancet. 1993;341(8852):1051-1054.

29. Foltz LM, Song KW, Connors JM. Hodgkin's lymphoma in adolescents. $J$ Clin Oncol. 2006;24(16):2520-2526.

30. Williams CD, Goldstone AH, Pearce R, et al. Autologous bone marrow transplantation for pediatric Hodgkin's disease: a casematched comparison with adult patients by the European Bone Marrow Transplant Group Lymphoma Registry. J Clin Oncol. 1993;11(11): 2243-2249.

31. Byrne BJ, Gockerman JP. Salvage therapy in Hodgkin's lymphoma. Oncologist. 2007;12(2):156-167.

32. Santoro A, Bredenfeld H, Devizzi L, et al. Gemcitabine in the treatment of refractory Hodgkin's disease: results of a multicenter phase II study. J Clin Oncol. 2000;18(13):2615-2619.

33. Venkatesh H, Di Bella N, Flynn TP, Vellek MJ, Boehm KA, Asmar L. Results of a phase II multicenter trial of single-agent gemcitabine in patients with relapsed or chemotherapy-refractory Hodgkin's lymphoma. Clin Lymphoma. 2004;5(2):110-115.

34. Zinzani PL, Bendandi M, Stefoni V, et al. Value of gemcitabine treatment in heavily pretreated Hodgkin's disease patients. Haematologica. 2000;85(9):926-929.

35. Aurer I, Radman I, Nemet D, et al. Gemcitabine in the treatment of relapsed and refractory Hodgkin's disease. Onkologie. 2005;28(11): 567-571.

36. Little R, Wittes RE, Longo DL, Wilson WH. Vinblastine for recurrent Hodgkin's disease following autologous bone marrow transplant. J Clin Oncol. 1998;16(2):584-588.

37. Devizzi L, Santoro A, Bonfante V, et al. Vinorelbine: an active drug for the management of patients with heavily pretreated Hodgkin's disease. Ann Oncol. 1994;5(9):817-820.

38. Rule S, Tighe M, Davies S, Johnson S. Vinorelbine in the treatment of lymphoma. Hematol Oncol. 1998;16(3):101-105.

39. Rancea M, Monsef I, von Tresckow B, et al. High-dose chemotherapy followed by autologous stem cell transplantation for patients with relapsed/refractory Hodgkin lymphoma. Cochrane Database Syst Rev. 2013;(6):CD009411.

40. Akhtar S, El Weshi A, Rahal M, Abdelsalam M, Al Husseini H, Maghfoor I. High-dose chemotherapy and autologous stem cell transplant in adolescent patients with relapsed or refractory Hodgkin's lymphoma. Bone Marrow Transplant. 2010;45(3):476-482.

41. Harris RE, Termuhlen AM, Smith LM, et al. Autologous peripheral blood stem cell transplantation in children with refractory or relapsed lymphoma: results of Children's Oncology Group study A5962. Biol Blood Marrow Transplant. 2011;17(2);249-258.

42. Nieto Y, Popat U, Anderlini P, et al. Autologous stem cell transplantation for refractory or poor-risk relapsed Hodgkin's lymphoma: effect of the specific high-dose chemotherapy regimen on outcome. Biol Blood Marrow Transplant. 2013;19(3):410-417.

43. William BM, Loberiza FR, Whalen V, et al. Impact of conditioning regimen on outcome of 2-year disease-free survivors of autologous stem cell transplantation for Hodgkin lymphoma. Clin Lymphoma Myeloma Leuk. 2013;13(4):417-422.

44. Bains T, Chen AI, Lemieux A, et al. Improved outcome with busulphan, melphalan and thiotepa conditioning in autologous hematopoietic stem cell transplant for relapsed/refractory Hodgkin lymphoma. Leuk Lymphoma. 2014;55(3):583-587.

45. Stewart DA, Guo D, Glück S, et al. Double high-dose therapy for Hodgkin's disease with dose-intensive cyclophosphamide, etoposide, and cisplatin (DICEP) prior to high-dose melphalan and autologous stem cell transplantation. Bone Marrow Transplant. 2000;26(4): 383-388.

46. Guilcher GM, Rizzuti FA, Lewis VA, Stewart DA. Single-agent high-dose melphalan followed by auto-SCT for relapsed and refractory Hodgkin lymphoma in children and adolescents. Bone Marrow Transplant. 2012;47(3):395-398. 
47. Baker KS, Gordon BG, Gross TG, et al. Autologous hematopoietic stem-cell transplantation for relapsed or refractory Hodgkin's disease in children and adolescents. J Clin Oncol. 1999;17(3):825-831.

48. Verdeguer A, Pardo N, Madero L, et al. Autologous stem cell transplantation for advanced Hodgkin's disease in children. Spanish group for BMT (GETMON), Spain. Bone Marrow Transplant. 2000;25(1):31-34.

49. Frankovich J, Donaldson SS, Lee Y, Wong RM, Amylon M, Verneris MR. High-dose therapy and autologous hematopoietic cell transplantation in children with primary refractory and relapsed Hodgkin's disease: atopy predicts idiopathic diffuse lung injury syndromes. Biol Blood Marrow Transplant. 2001;7(1):49-57.

50. Lazarus HM, Rowlings PA, Zhang MJ, et al. Autotransplants for Hodgkin's disease in patients never achieving remission: a report from the Autologous Blood and Marrow Transplant Registry. J Clin Oncol. 1999; 17(2):534-545

51. Metzger ML, Hudson MM, Krasin MJ, et al. Initial response to salvage therapy determines prognosis in relapsed pediatric Hodgkin lymphoma patients. Cancer. 2010;116(18):4376-4384.

52. Josting A, Muller H, Borchmann P, et al. Dose intensity of chemotherapy in patients with relapsed Hodgkin's lymphoma. J Clin Oncol. 2010;28(34):5074-5080.

53. Devillier R, Coso D, Castagna L, et al. Positron emission tomography response at the time of autologous stem cell transplantation predicts outcome of patients with relapsed and/or refractory Hodgkin's lymphoma responding to prior salvage therapy. Haematologica. 2012;97(7): 1073-1079.

54. Morschhauser F, Brice P, Ferme C, et al. Risk-adapted salvage treatment with single or tandem autologous stem-cell transplantation for first relapse/refractory Hodgkin's lymphoma: results of the prospective multicenter H96 trial by the GELA/SFGM study group. J Clin Oncol. 2008;26(36):5980-5987.

55. Sibon DR, Morschhauser F, Ferme C, et al. Long-term outcome of adults with first relapse or refractory Hodgkin lymphoma treated in the prospective LYSA/SFGM-TC H96 trial. Oral presentation at: International Conference on Malignant Lymphoma; June 22, 2013; Lugano, Switzerland.

56. Reece DE, Connors JM, Spinelli JJ, et al. Intensive therapy with cyclophosphamide, carmustine, etoposide \pm cisplatin, and autologous bone marrow transplantation for Hodgkin's disease in first relapse after combination chemotherapy. Blood. 1994;83(5)1193-1199.

57. Chopra R, McMillan AK, Linch DC, et al. The place of high-dose BEAM therapy and autologous bone marrow transplantation in poor-risk Hodgkin's disease. A single-center eight-year study of 155 patients Blood. 1993;81(5):1137-1145.

58. Stewart DA, Guo D, Sutherland JA, et al. Single-agent high-dose melphalan salvage therapy for Hodgkin's disease: cost, safety, and long-term efficacy. Ann Oncol. 1997;8(12):1277-1279.

59. Bosch M, Khan FM, Storek J. Immune reconstitution after hematopoetic cell transplantation. Curr Opin Hematol. 2012;19(4):324-335.

60. Kameoka Y, Takahashi N, Ishizawa K, et al. Safety and feasibility of high-dose ranimustine (MCNU), carboplatin, etoposide, and cyclophosphamide (MCVC) therapy followed by autologous stem cell transplantation for malignant lymphoma. Int J Hematol. 2012;96(5):624-630.

61. Kreissman SG, Seeger RC, Matthay KK, et al. Purged versus nonpurged peripheral blood stem-cell transplantation for high-risk neuroblastoma (COG A3973): a randomised phase 3 trial. Lancet Oncol. 2013;14(10):999-1008.

62. Minn AY, Riedel E, Halpern J, et al. Long-term outcomes after highdose therapy and autologous haematopoietic cell rescue for refractory/ relapsed Hodgkin lymphoma. Br J Haematol. 2012;159(3):329-339.

63. Forrest DL, Hogge DE, Nevill TJ, et al. High-dose therapy and autologous hematopoietic stem-cell transplantation does not increase the risk of second neoplasms for patients with Hodgkin's lymphoma: a comparison of conventional therapy alone versus conventional therapy followed by autologous hematopoietic stem-cell transplantation. J Clin Oncol. 2005;23(31):7994-8002.
64. Andre M, Henry-Amar M, Blaise D, et al. Treatment-related deaths and second cancer risk after autologous stem-cell transplantation for Hodgkin's disease. Blood. 1998;92(6):1933-1940.

65. Pedersen-Bjergaard J, Pedersen M, Myhre J, Geisler C. High risk of therapy-related leukemia after BEAM chemotherapy and autologous stem cell transplantation for previously treated lymphoma is mainly related to primary chemotherapy and not to the BEAM-transplantation procedure. Leukemia. 1997;11(10):1654-1660.

66. Bhatia S, Robison LL, Francisco L, et al. Late mortality in survivors of autologous hematopoietic-cell transplantation: report from the Bone Marrow Transplant Survivor Study. Blood. 2005;105(11): 4215-4222.

67. Barton SE, Najita JS, Ginsburg ES, et al. Infertility, infertility treatment, and achievement of pregnancy in female survivors of childhood cancer: a report from the Childhood Cancer Survivor Study cohort. Lancet Oncol. 2013;14(9):873-881.

68. Pizzo PA, Poplack DG, editors. Principles and Practice of Pediatric Oncology. 5th ed. New York: Lippincott Williams and Wilkins; 2006.

69. Appelbaum FR, Forman SJ, Negrin RS, Blume KG, editors. Thomas' Hematopoietic Cell Transplantation. 4th ed. Hoboken, NJ: Wiley-Blackwell; 2004.

70. Yeomanson DJ, Morgan S, Pacey AA. Discussing fertility preservation at the time of cancer diagnosis: dissatisfaction of young females. Pediatr Blood Cancer. 2013;60(12):1996-2000.

71. Yee S, Buckett W, Campbell S, Yanofsky R, Barr RD. A national study of the provision of oncofertility services to female patients in Canada. J Obstet Gynaecol Can. 2012;34(9):849-858.

72. Ayensu-Coker L, Bauman D, Lindheim SR, Breech L. Fertility preservation in pediatric, adolescent and young adult female cancer patients. Pediatr Endocrinol Rev. 2012;10(1):174-187.

73. Detti L, Martin DC, Williams LJ. Applicability of adult techniques for ovarian preservation to childhood cancer patients. J Assist Reprod Genet. 2012;29(9):985-995.

74. Goodman KA, Riedel E, Serrano V, Gulati S, Moskowitz CH, Yahalom J. Long-term effects of high-dose chemotherapy and radiation for relapsed and refractory Hodgkin lymphoma. J Clin Oncol. 2008;26(32):5240-5247.

75. Brandt J, Dietrich S, Meissner J, Neben K, Ho AD, Witzens-Harig M. Quality of life of long-term survivors with Hodgkin lymphoma after high-dose chemotherapy, autologous stem cell transplantation, and conventional chemotherapy. Leuk Lymphoma. 2010;51(11): 2012-2020.

76. Behringer K, Müller H, Görgen H, et al. Sexual quality of life in Hodgkin lymphoma: a longitudinal analysis by the German Hodgkin Study Group. Br J Cancer. 2013;108(1):49-57.

77. Poen JC, Hoppe RT, Horning SJ. High-dose therapy and autologous bone marrow transplantation for relapsed/refractory Hodgkin's disease: the impact of involved field radiotherapy on patterns of failure and survival. Int J Radiat Oncol Biol Phys. 1996;36(1):3-12.

78. Wadhwa P, Shina DC, Schenkein D, Lazarus HM. Should involved-field radiation therapy be used as an adjunct to lymphoma autotransplantation? Bone Marrow Transplant. 2002;29(3):183-189.

79. Kahn S, Flowers C, Xu Z, Esiashvili N. Does the addition of involved field radiotherapy to high-dose chemotherapy and stem cell transplantation improve outcomes for patients with relapsed/refractory Hodgkin lymphoma? Int J Radiat Oncol Biol Phys. 2011;81(1): 175-180.

80. Biswas T, Culakova E, Friedberg JW, et al. Involved field radiation therapy following high dose chemotherapy and autologous stem cell transplant benefits local control and survival in refractory or recurrent Hodgkin lymphoma. Radiother Oncol. 2012;103(3):367-372.

81. Wendland MM, Asch JD, Pulsipher MA, Thomson JW, Shrieve DC, Gaffney DK. The impact of involved field radiation therapy for patients receiving high-dose chemotherapy followed by hematopoietic progenitor cell transplant for the treatment of relapsed or refractory Hodgkin disease. Am J Clin Oncol. 2006;29(2):189-195. 
82. MundtAJ, Sibley G, Williams S, Hallahan D, Nautiyal J, Weichselbaum RR. Patterns of failure following high-dose chemotherapy and autologous bone marrow transplantation with involved field radiotherapy for relapsed/refractory Hodgkin's disease. Int J Radiat Oncol Biol Phys. 1995;33(2):261-270.

83. Lancet JE, Rapoport AP, Brasacchio R, et al. Autotransplantation for relapsed or refractory Hodgkin's disease: long-term follow-up and analysis of prognostic factors. Bone Marrow Transplant. 1998;22(3): 265-271.

84. Goda JS, Massey C, Kuruvilla J, et al. Role of salvage radiation therapy for patients with relapsed or refractory Hodgkin lymphoma who failed autologous stem cell transplant. Int J Radiat Oncol Biol Phys. 2012;84(3):e329-e335.

85. Fox AM, Dosoretz AP, Mauch PM, et al. Predictive factors for radiation pneumonitis in Hodgkin lymphoma patients receiving combined-modality therapy. Int J Radiat Oncol Biol Phys. 2012;83(1): 277-283.

86. Kaloyannidis P, Voutiadou G, Baltadakis I, et al. Outcomes of Hodgkin's lymphoma patients with relapse or progression following autologous hematopoietic cell transplantation. Biol Blood Marrow Transplant. 2012;18(3):451-457.
87. Batlevi CL, Younes A. Novel therapy for Hodgkin lymphoma. Hematology Am Soc Hematol Educ Program. 2013;2013:394-399.

88. Younes A. Brentuximab vedotin for the treatment of patients with Hodgkin lymphoma. Hematol Oncol Clin North Am. 2014;28(1):27-32.

89. Younes A, Gopal AK, Smith SE, et al. Results of a pivotal phase II study of brentuximab vedotin for patients with relapsed or refractory Hodgkin's lymphoma. J Clin Oncol. 2012;30(18):2183-2189.

90. Sasse S, Rothe A, Goergen H, et al. Brentuximab vedotin (SGN-35) in patients with transplant-naive relapsed/refractory Hodgkin lymphoma. Leuk Lymphoma. 2013;54(10):2144-2148.

91. Corazelli G, Angrilli F, D’Arco A, et al. Efficacy and safety of bendamustine for the treatment of patients with recurring Hodgkin lymphoma. Br J Haematol. 2013;160(2):207-215.

92. Younes A, Oki Y, McLaughlin P, et al. Phase 2 study of rituximab plus ABVD in patients with newly diagnosed classical Hodgkin lymphoma. Blood. 2012;119(18):4123-4128.
Clinical Oncology in Adolescents and Young Adults

\section{Publish your work in this journal}

Clinical Oncology in Adolescents and Young Adults is an international, peer-reviewed, open access journal publishing original research, reports, editorials, reviews and commentaries on all aspects of epidemiology, diagnosis and treatment of cancers in adolescents and young adults. The manuscript management system is completely

\section{Dovepress}

online and includes a very quick and fair peer-review system. Visit http://www.dovepress.com/testimonials.php to read real quotes from published authors.

\footnotetext{
Submit your manuscript here: http://www.dovepress.com/clinical-oncology-in-adolescents-and-young-adults-journal
} 